\title{
Aortic replacement for bicuspid aortic valve aortopathy: When and why?
}

\author{
Alan C. Braverman, MD \\ From the Cardiovascular Division, Department of Medicine, Washington University in St Louis School of \\ Medicine, St Louis, Mo. \\ Received for publication April 12, 2018; revisions received May 22, 2018; accepted for publication June 4, 2018; \\ available ahead of print July 25, 2018. \\ Address for reprints: Alan C. Braverman, MD, 660 S Euclid Ave, Box 8086, St Louis, MO 63110 (E-mail: \\ abraverm@wustl.edu). \\ J Thorac Cardiovasc Surg 2019;157:520-5 \\ $0022-5223 / \$ 36.00$ \\ Copyright (c) 2018 by The American Association for Thoracic Surgery \\ https://doi.org/10.1016/j.jtcvs.2018.06.023
}

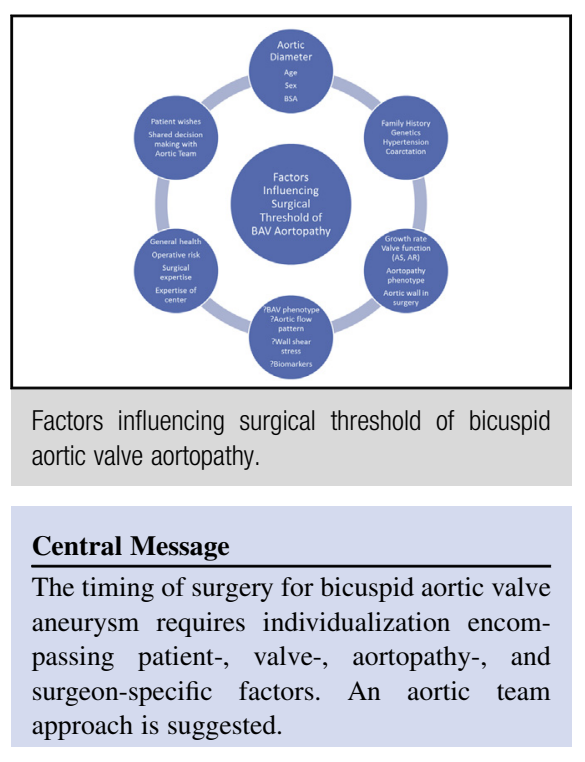

See Editorial Commentary page 526.
The bicuspid aortic valve (BAV) is the most common congenital heart valve defect, affecting approximately $1 \%$ of the population. In addition to valvular lesions and congenital defects, BAV is associated with aortopathy, which may lead to aortic root and/or ascending aortic aneurysm and risk for aortic dissection. BAV aortopathy has a wide spectrum of presentation, ranging from an aortic root and/or ascending aneurysm in young patients with familial disease to that found incidentally late in life during evaluation of an asymptomatic heart murmur.

The surgical threshold for prophylactic aortic aneurysm resection in BAV aortopathy requires complex decision making and has been the subject of debate ${ }^{1}$ (Figure 1). The 2014 American College of Cardiology (ACC)/American Heart Association (AHA) valve guidelines recommended (class I recommendation) prophylactic replacement of the aortic root and/or ascending aorta in adults with BAV when the aortic dimension exceeds $5.5 \mathrm{~cm} .^{2}$ Surgery for BAV aortic aneurysm of $>5 \mathrm{~cm}$ was suggested (a class IIa indication) in the presence of risk factors for aortic dissection, such as a family history of aortic dissection or rapid growth of the aorta $(>0.5 \mathrm{~cm} /$ year). Aortic resection was also suggested if the aorta was $>4.5 \mathrm{~cm}$ and the primary indication for surgery was severe valvular disease. In practice, very few patients with BAV disease have a family history of aortic dissection or such rapid growth of the aorta. Thus, the 2014 ACC/AHA valve guidelines suggested that most BAV patients with a 5-cm aortic aneurysm should be "observed." It was opined that patients with a BAV aortic aneurysm are at no greater risk of aortic dissection than those with an aneurysm associated with a tricuspid aortic valve (TAV) and can be managed in a similar manner. ${ }^{2}$
Multiple recent guidelines have provided expert consensus opinions regarding the aortic diameter at which to recommend prophylactic aneurysm surgery for BAV aortopathy. How do the clinician and surgeon factor patient-specific characteristics into an algorithm for shared decision making about the timing of prophylactic aortic surgery? Is it appropriate to "watch and wait" for all those with BAV aneurysm of 5 to $5.5 \mathrm{~cm}$ ? BAV aneurysm disease differs from TAV aneurysm disease, with aneurysms occurring earlier in life, and aortic dissections in patients with a BAV are overrepresented (present in 4\%-10\%) in series of ascending dissections, especially in young patients. $^{1-5}$ Ascending aortic aneurysms in BAV differ from those in TAV, showing increased apoptosis, more elastic fragmentation, altered expression of matrix metalloproteinases (MMPs), lower fibrillin-1 content, and increased collagen-related stiffness. ${ }^{1}$

Patients with BAV followed in community or tertiary centers who undergo serial imaging follow-up and timely prophylactic aortic surgery for aneurysm disease have a very low risk of aortic dissection and a life expectancy similar to controls. . $^{3,6,7}$ Of 212 BAV patients aged $32 \pm 20$ years, only $15 \%$ had an aortic diameter $>40 \mathrm{~mm}$ at entry. Over 20 years of follow-up, 5\% underwent aneurysm surgery, and there were no aortic dissections. ${ }^{6}$ Among 642 patients with BAV (mean age $35 \pm 16$ years) followed for a mean of 9 years, $20 \%$ developed aortic 


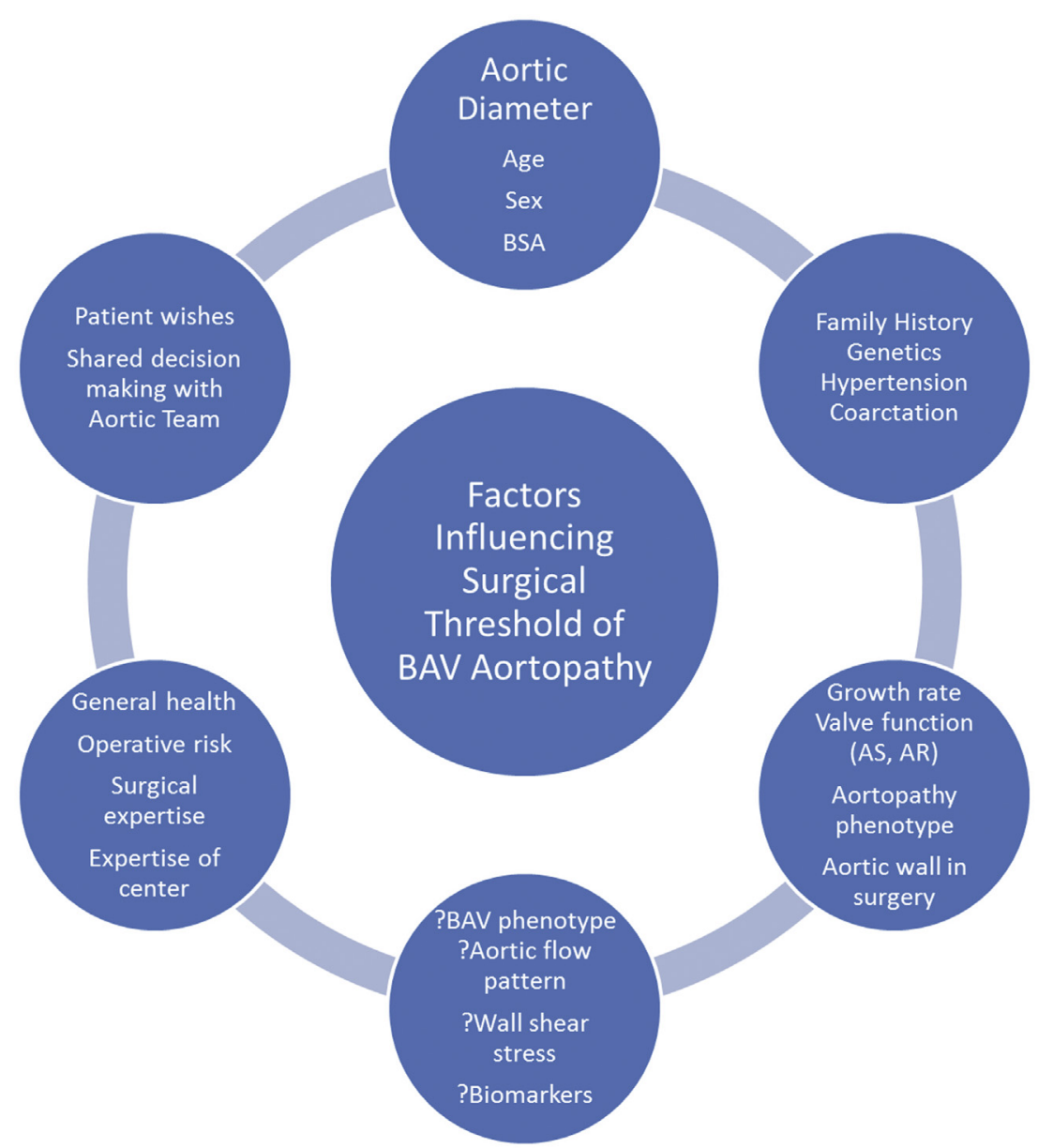

FIGURE 1. Factors influencing surgical threshold of bicuspid aortic valve aortopathy. BSA, Body surface area; $A S$, aortic stenosis; $A R$, aortic regurgitation.

dilatation $(>40 \mathrm{~mm})$, and $29 \%$ of patients who underwent aortic valve replacement (AVR) also underwent aneurysm resection. Five aortic dissections occurred during follow-up, with a population risk of $0.1 \%$ per patient/year. ${ }^{7}$ Among 416 patients with BAV followed for a mean of $16 \pm 7$ years, there were 2 aortic dissections, with an incidence of 3.1 per 10,000 patient-years, and an age-adjusted risk relative risk of $8.4 .^{3}$ The prognosis is less favorable for BAV patients with aortic dilatation, however. Among those with aortic aneurysm ( $\geq 45 \mathrm{~mm})$, the aortic dissection risk was 44.9 per 10,000 person-years, representing a 150-fold greater risk of dissection compared with population controls ( 0.31 per 10,000 person-years). Importantly, almost one-half of the 32 patients with an aneurysm $\geq 45 \mathrm{~mm}$ underwent aortic surgery, and $6 \%$ suffered aortic dissection during a 15-year follow-up. ${ }^{3}$

Do we know the "natural history" of BAV aneurysm disease, and can we predict the risk of aortic dissection while observing the patient with an aortic diameter of $\geq 5 \mathrm{~cm}$ in each sex, at various ages, and with other risk factors? Unfortunately, there are little data from this at-risk population to inform decision making. Data on the risk of aortic dissection was sought from an echocardiography database of 4654 "nonsyndromic" adults with a dilated ascending aorta (40-55 mm), of whom $12.6 \%$ had a BAV (mean age $54 \pm 14$ years), and $81.4 \%$ had a TAV (mean age, $71 \pm 12$ years). ${ }^{4}$ The aortic growth rate was significantly higher in patients with BAVs. In this cohort, only $3.8 \%$ of patients underwent elective aneurysm repair, and there were very few aortic events $(\sim 0.2 \%)$ during an average follow-up of 40 months. However, very few patients $(2.8 \%)$ had an aortic diameter $\geq 50 \mathrm{~mm}$, and there were only $9 \mathrm{BAV}$ patients with follow-up once the aorta reached $50 \mathrm{~mm}$, preventing meaningful risk estimation. The largest dataset comes from the Cleveland Clinic, which reported outcomes of 1181 BAV patients with aortic diameter $>4.7 \mathrm{~cm}$ at the aortic root or ascending aorta. ${ }^{8}$ Aneurysm repair $(68 \%$ with concomitant aortic valve surgery) was performed in 801 patients. The 380 patients who did not undergo surgery were observed for a median of 3 years (range, 0-17 years); 

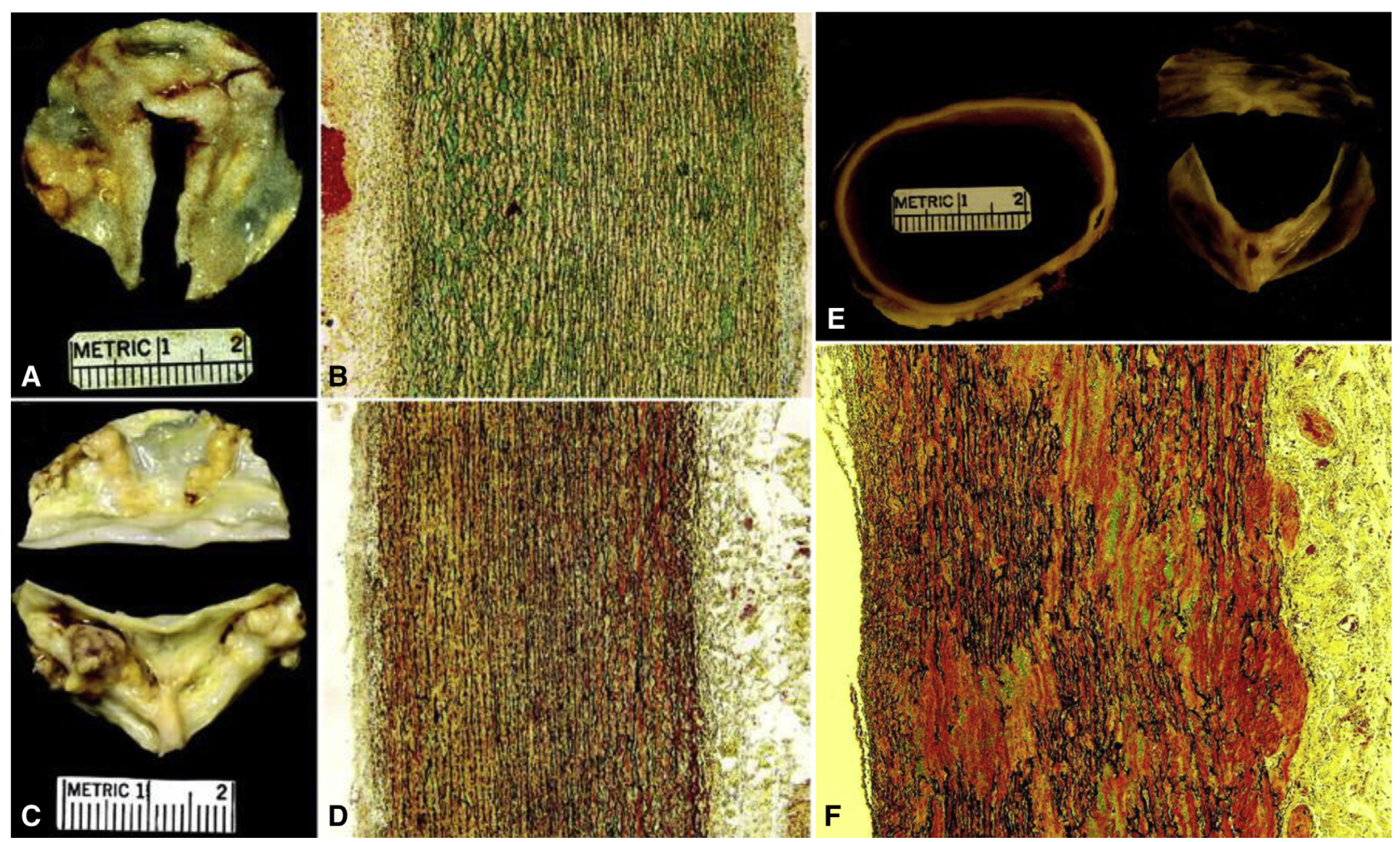

FIGURE 2. Bicuspid aortic morphology and aortic wall pathology. A and B, Photographs of an operatively excised unicommissural unicuspid stenotic (and regurgitant) aortic valve (A) and histological section (B) of the histologically normal aorta in a 41-year-old woman. C and D, Photographs of an operatively excised congenitally bicuspid stenotic aortic valve (C) and histological section (D) of the ascending aorta in a 77-year-old man showing a $1+/ 4+$ loss of medial elastic fibers. E, Photograph of an operatively excised purely regurgitant congenitally bicuspid aortic valve and a portion of resected aorta in a 54-year-old man. F, Histological section of ascending aorta (maximal diameter, $6.7 \mathrm{~cm}$ ) showing a $3+/ 4+$ loss of medial elastic fibers. (B, D, and F: Movat staining; original magnification $100 \times$.) (Reproduced with permission. ${ }^{10}$ )

175 of the 380 had aortic surgery during follow-up. Ten of 380 patients $(2.6 \%)$ suffered a type A dissection. The risk-adjusted probability of dissection was $4 \%$ at an aortic root diameter of $5 \mathrm{~cm}$ and $3.8 \%$ at an ascending aortic diameter of $5.3 \mathrm{~cm} .{ }^{8}$ These data provide some insight into the risk for selected BAV patients with aneurysm disease.

Should we treat all BAV patients with aortic root and/or ascending aortic aneurysm the same? I think not. There are many factors to consider when contemplating preventative aortic aneurysm resection, including age, sex, body size, aortopathy phenotype, valve lesion, aortic growth rate, family history, hypertension, aortic coarctation, appearance of the aorta at surgery, surgical expertise, and patient wishes. The rationale for individualization of surgical thresholds is discussed below.

Is the risk of aortic dissection the same for a $5-\mathrm{cm}$ aortic aneurysm in a 25-year-old woman (body surface area [BSA], $1.75 \mathrm{~m}^{2}$ ), whose expected aortic diameter is $2.9 \mathrm{~cm}$, and in a 60-year-old man (BSA, $2.2 \mathrm{~m}^{2}$ ), whose expected aortic diameter is $3.7 \mathrm{~cm}$ ? In each patient, the expected aortic size has a $z$-score of 0 , whereas the $5-\mathrm{cm}$ aortic aneurysm corresponds to a $z$-score of and 8 and 4.9, respectively, and an aortic size index of 2.9 and 2.3, respectively. Aortic size is related to age, height, BSA, and sex. ${ }^{1}$ Aortic complications are recognized to correlate better with the aortic size indexed to body size than to diameter alone. ${ }^{9}$ This is also true for BAV aneurysm disease. $^{8}$

The function of the BAV (whether regurgitant or stenotic), the aortopathy phenotype (root, ascending, diffuse/arch), the aortic growth rate, and the presence of coarctation and hypertension inform the risk of aortic complication. ${ }^{1}$ Guidelines provide for the consideration of earlier surgery for those with a BAV aneurysm who have hypertension or exhibit rapid aortic growth (defined variably as $>2-5 \mathrm{~mm} / \mathrm{year}){ }^{1}$ Coarctation of the aorta is also associated with aortic risk with a BAV, because the presence of a BAV increases the risk of subsequent aortic wall complications in patients with coarctation. ${ }^{1}$ The degree of aortic dilatation is greater in BAV patients with aortic regurgitation (AR) than in those with aortic stenosis (AS). ${ }^{1}$ Among patients with BAV undergoing AVR and aneurysm resection, cystic medial degeneration is much more common and more severe when the underlying valve 


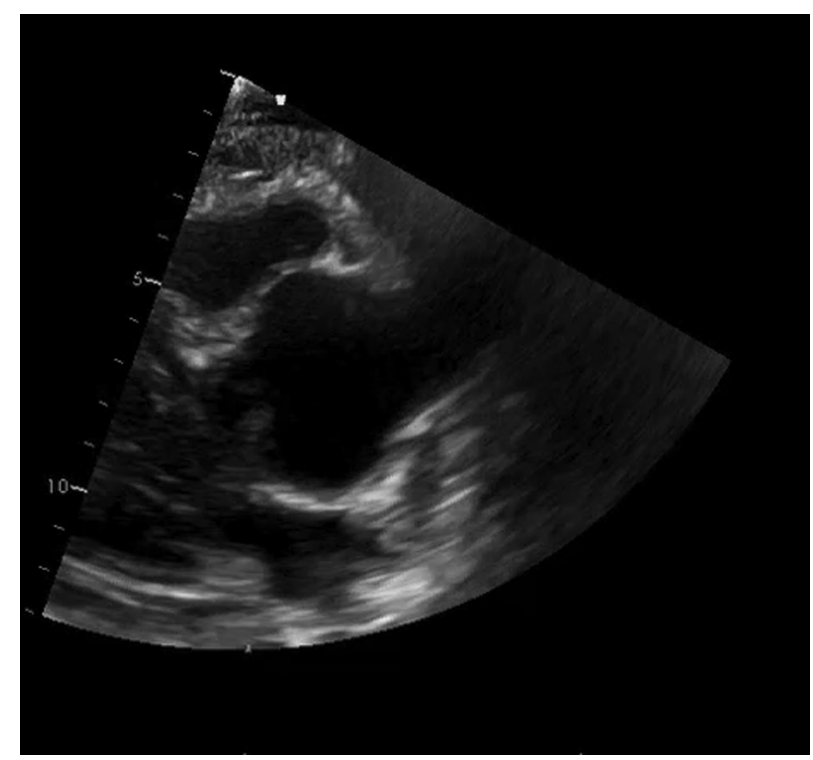

VIDEO 1. Bicuspid aortic valve with a dilated aortic root measuring $4.8 \mathrm{~cm}$ visualized on transthoracic echocardiogram. There is right-left coronary cusp fusion and a raphe present. Video available at: https://www.jtcvs.org/article/S0022-5223(18)31757-4/fulltext.

lesion is $\mathrm{AR}$ than when it is $\mathrm{AS}^{10}$ (Figure 2). Aortic dissection is also more prevalent late after AVR when performed for BAV-AR than for AS. A meta-analysis of isolated AVR for BAV compared previous AR and AS, enabling a comparison of underlying valve disease and late aortic dissection risk. ${ }^{11}$ Despite having smaller aortic diameters at the time of AVR (mean, $46 \pm 5 \mathrm{~mm}$ vs $52 \pm 5 \mathrm{~mm}$ ), BAV-AR was associated with a $>10$-fold greater risk of late post-AVR aortic dissection $(2.8 \%$ vs $0.2 \%$ ) compared with BAV-AS. ${ }^{11}$

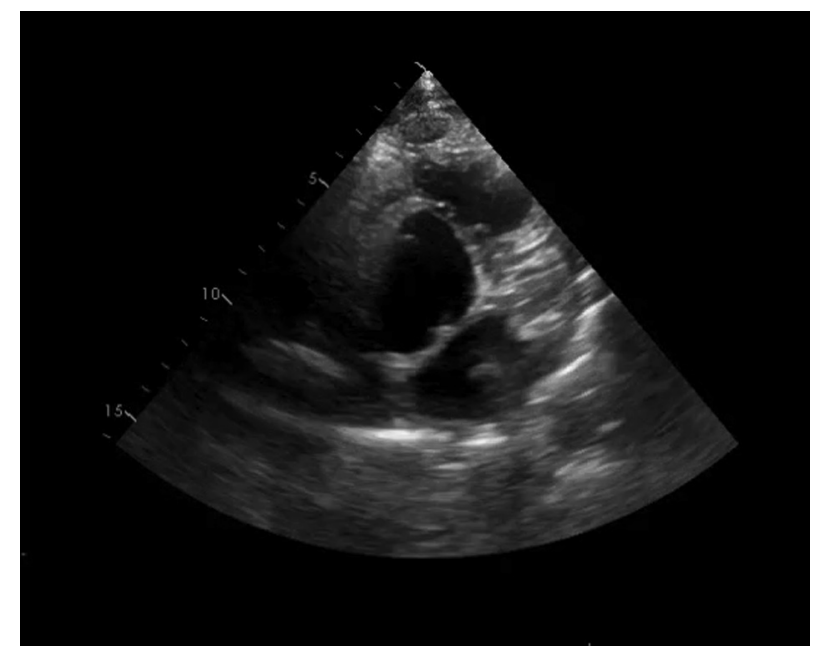

VIDEO 2. Dilated ascending aorta measuring $5 \mathrm{~cm}$ in a patient with bicuspid aortic valve. Note the normal diameter of the aortic sinuses. Video available at: https://www.jtcvs.org/article/S0022-5223(18)31757-4/fulltext.
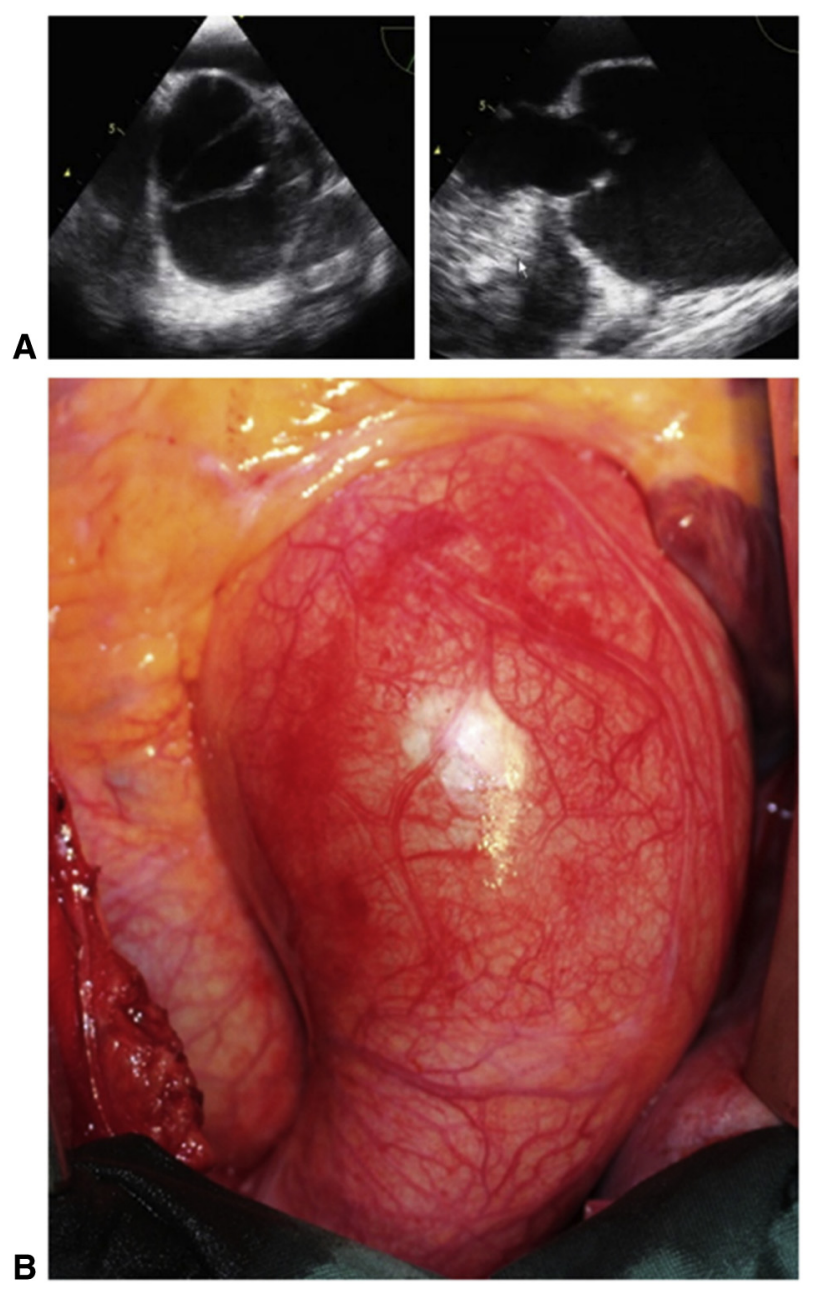

FIGURE 3. Transthoracic echocardiography (A) and intraoperative findings (B) in the bicuspid aortic valve root phenotype. (Reproduced with permission from Girdauskas E, Borger MA. Bicuspid aortic valve and associated aortopathy: an update. Semin Thorac Cardiovasc Surg. 2013;25:310-316.)

There are multiple phenotypes of BAV aortopathy. Is aortic risk the same for each? (Videos 1 and 2). The root phenotype, present in $10 \%$ to $15 \%$ of patients, has predominant root dilatation, a dilated annulus, and associated AR; occurs at a younger age; and has a higher prevalence of a genetic trigger ${ }^{1,12,13}$ (Figure 3). The root phenotype is also associated with increased risk of late aortic events after AVR. Girdauskas and colleagues ${ }^{12}$ followed $56 \mathrm{BAV}$ patients (mean age, $47 \pm 11$ years) with the root phenotype who underwent isolated AVR for AR in the presence of aortic root dilatation $(40-50 \mathrm{~mm}){ }^{12}$ During follow-up (mean, $11.1 \pm 3.6$ years), $34 \%$ of patients suffered an aortic event (including aortic dissection, progressive aneurysmal dilatation, aortic aneurysm surgery, and sudden death), and only $50 \%$ were free of an aortic event at 15 years. ${ }^{12}$ Prophylactic surgery should be considered for root phenotype BAV aneurysms of $\geq 5 \mathrm{~cm}$ 

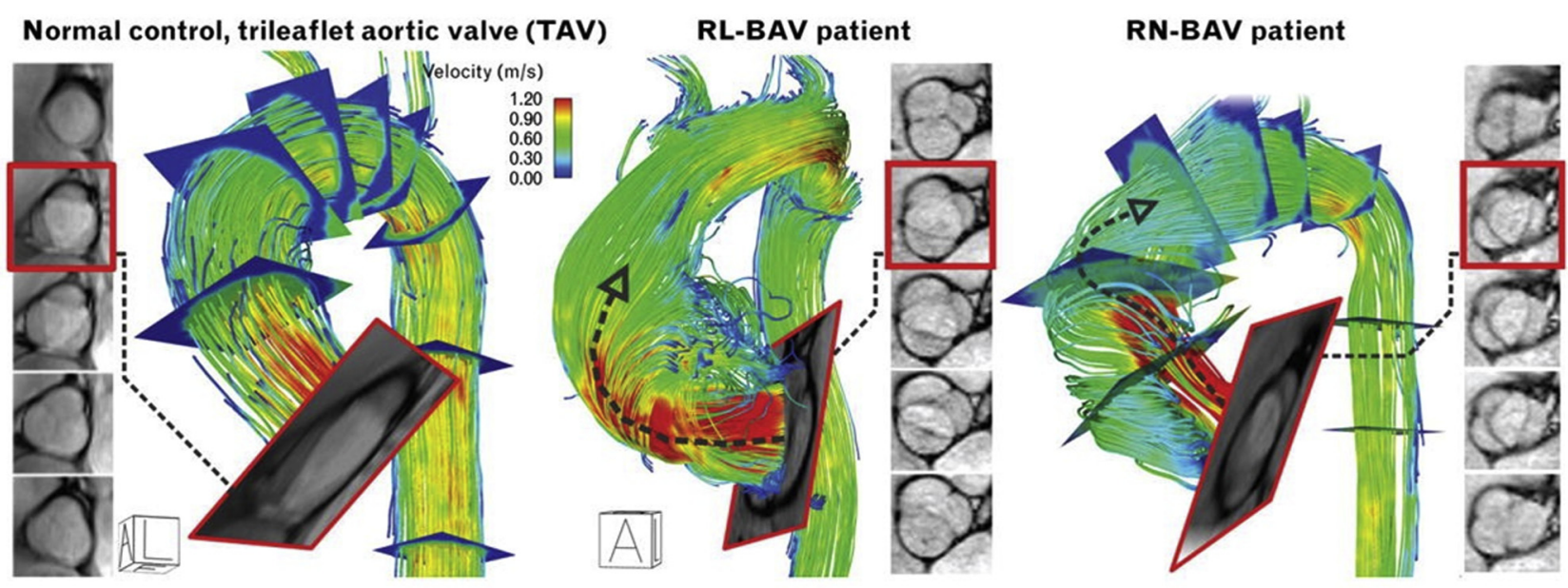

FIGURE 4. Four-dimensional magnetic resonance imaging of bicuspid aortic valve (BAV)-mediated hemodynamics. Images show control and BAV patient with a right-left (RL) and right-noncoronary (RN) fusion pattern. Note that right and left coronary leaflet BAV resulted in a marked eccentric aortic outflow jet (but not higher velocity; arrow) impinging on the aortic wall compared with the trileaflet aortic valve. The BAV phenotype (RL vs RN) strongly impacts aortic outflow and thus the aortic regions exposed to elevated wall shear stress. (Reproduced with permission from Fedak PW, Barker AJ, Verma S. Year in review: bicuspid aortopathy. Curr Opin Cardiol. 2016;31:132-138; and Barker and colleagues. ${ }^{17}$ )

in appropriate candidates, considering that root replacement is more complex and carries a greater risk than ascending aortic aneurysm resection. For most patients with BAV ascending aneurysm disease, complete root replacement surgery is not required. The long-term risk of aortic root dilatation post-AVR is low, and root replacement may be considered for BAV disease when the root diameter exceeds $4.5 \mathrm{~cm}$ in patients undergoing AVR. ${ }^{14}$

Hemodynamic factors influence BAV aortopathy and may predict future aortic risks. The BAV exhibits abnormal leaflet folding, wrinkling, and doming, leading to turbulence in the absence of valve stenosis. ${ }^{15}$ Abnormal ascending aortic wall shear stress and abnormal helical flow accompanies BAV irrespective of whether an aortic aneurysm is present. ${ }^{1,16}$ The BAV valve phenotype (leaflet fusion type) and lesion (AS or AR) are correlated with aortopathy type. ${ }^{13}$ Four-dimensional magnetic resonance imaging studies demonstrate that the BAV phenotype impacts aortic flow patterns and aortic wall shear stress ${ }^{17}$ (Figure 4). The right-left coronary cusp fusion is associated with a right anterior jet, increased wall stress at the convexity (outer curvature of the aorta), and aortic dilatation at the convexity. The right-noncoronary cusp fusion associates with an eccentric left posterior jet, increased wall stress on the lesser curvature of the aorta, and tubular aortic enlargement extending into the arch. Furthering the relationship between BAV valve phenotype and aortopathy, 4-dimensional magnetic resonance imaging flow-mapping combined with tissue sampling at aneurysmectomy correlates increased wall shear stress to areas of cystic medial degeneration and alterations in regulatory proteins, including MMPs and transforming growth factor $\beta .{ }^{18}$ Currently under investigation, circulating biomarkers, including MMPs and inhibitors, transforming growth factor $\beta$, soluble receptor for advanced glycation end products, and micro-RNAs, have the potential to inform aortic risk in BAV disease. ${ }^{19}$

Individual decision making is especially relevant when managing BAV patients who are facing primary aortic valve surgery for severe AS or AR and have aortic dilatation. Late aortic events are uncommon in BAV patients with a normal or mildly enlarged aortic diameter at the time of AVR alone. ${ }^{20}$ Only 3 of $1449 \mathrm{BAV}$ patients who underwent AVR had a late aortic events when the aortic diameter was $<4.5 \mathrm{~cm}$ at the time of valve surgery. ${ }^{21}$ However, BAV patients with a dilated aortic root phenotype and primary AR are at greater risk of late aortic events after AVR alone. ${ }^{11,12}$ Concomitant aortic aneurysm repair is considered reasonable (class IIa indication) for BAV patients undergoing primary valve surgery when the aortic diameter is $>4.5 \mathrm{~cm} .^{2,22}$ Experienced centers consider multiple factors when planning aortic surgery for BAV patients facing primary valve surgery with outstanding results. $^{21,23}$

In response to input from societies and individuals, in 2016, the ACC/AHA issued a statement of clarification to address concerns about the 2014 recommendations for management of aortic aneurysms complicating BAV. ${ }^{22}$ The updated guidelines include a class I indication for BAV-associated aneurysm surgery when the aorta is $\geq 5.5 \mathrm{~cm}$. The guidelines were also revised to state that surgical resection for $\mathrm{BAV}$-associated aneurysm is reasonable if the aortic root and/or ascending aorta is $\geq 5 \mathrm{~cm}$ in diameter and an additional risk factor for aortic 
dissection is present (ie, family history of dissection or aortic growth $>5 \mathrm{~mm} /$ year) or if the patient is at low surgical risk $(<4 \%)$ and the surgery is performed by an experienced aortic surgical team with established expertise in these procedures. $^{22}$ These guidelines provide an important balance considering the wide spectrum of patients being considered for surgery.

The 2018 American Association for Thoracic Surgery consensus guidelines on bicuspid aortic valve-related aortopathy provide support for a surgical threshold for a BAV aortic aneurysm of $5.5 \mathrm{~cm}$ for "routine replacement" of the ascending aorta in the absence of valve indications for surgery. ${ }^{14}$ The guidelines also state that earlier intervention (ie, when the aorta is $\geq 5 \mathrm{~cm}$ ) may be considered for patients with the following characteristics: (1) risk factors for dissection (eg, aortic coarctation, family history of dissection, rapid aortic growth [>3-5 mm/year]); (2) small BSA or stature; (3) strong preference for early surgery; and (4) low operative risk, with the procedure performed by an experienced operative team with established results. Notable experts also emphasize individualization in surgical decision making based not only on the aortic diameter, but also including aortopathy phenotype and other patient-specific factors. ${ }^{24,25}$ One would not expect a 30 -year-old with a BAV and a 5-cm aortic root aneurysm with moderate aortic regurgitation to be managed the same as a 75-year-old with a 5-cm mid-ascending aortic aneurysm and mild BAV aortic stenosis. The timing of aneurysm resection in BAV aortopathy requires individual decision making incorporating aortic diameter and many other factors as well (Figure 1). The surgical risks must be weighed against the risks of aortic complications. The patient's age, size, sex, aortopathy phenotype, valve lesion, and operative risk and the expertise of the surgeon and center also inform decision making for BAV aortopathy. The future promises even more individualization incorporating precision medicine. As has worked well in the management of other complex cardiovascular disorders, an aortic team approach may best serve patients with BAV and aortopathy.

\section{Conflict of Interest Statement}

Author has nothing to disclose with regard to commercial support.

\section{References}

1. Adamo L, Braverman AC. Surgical threshold for bicuspid aortic valve aneurysm: a case for individual decision-making. Heart. 2015;101:1361-7.

2. Nishimura RA, Otto CM, Bonow RO, Carabello BA, Erwin JP III, Guyton RA, et al. 2014 AHA/ACC guideline for the management of patients with valvular heart disease: a report of the American College of Cardiology/American Heart Association task force on practice guidelines. J Thorac Cardiovasc Surg. 2014; 148:e1-132.

3. Michelena HI, Khanna AD, Mahoney D, Margaryan E, Topilsky Y, Suri RM, et al. Incidence of aortic complications in patients with bicuspid aortic valves. JAMA. 2011;306:1104-12.
4. Kim JB, Spotnitz M, Lindsay ME, MacGillivray TE, Isselbacher EM, Sundt TM III. Risk of aortic dissection in the moderately dilated ascending aorta J Am Coll Cardiol. 2016;68:1209-19.

5. Etz CD, von Aspern K, Hoyer A, Girrbach FF, Leontyev S, Bakhtiary F, et al. Acute type A aortic dissection: characteristics and outcomes comparing patients with bicuspid versus tricuspid aortic valve. Eur J Cardiothorac Surg. 2015;48:142-50.

6. Michelena HI, Desjardins VA, Avierinos JF, Russo A, Nkomo VT, Sundt TM, et al. Natural history of asymptomatic patients with normally functioning or minimally dysfunctional bicuspid aortic valve in the community. Circulation. 2008; 117:2776-84.

7. Tzemos N, Therrien J, Yip J, Thanassoulis G, Tremblay S, Jamorski MT, et al. Outcomes in adults with bicuspid aortic valves. JAMA. 2008;300:1317-25.

8. Wojnarski CM, Svensson LG, Roselli EE, Idrees JJ, Lowry AM, Ehrlinger J, et al. Aortic dissection in patients with bicuspid aortic valve-associated aneurysms. Ann Thorac Surg. 2015;100:1666-73; discussion 1673-4.

9. Davies RR, Gallo A, Coady MA, Tellides G, Botta DM, Burke B, et al. Novel measurement of relative aortic size predicts rupture of thoracic aortic aneurysms. Ann Thorac Surg. 2006;81:169-77.

10. Roberts WC, Vowels TJ, Ko JM, Filardo G, Hebeler RF Jr, Henry AC, et al Comparison of the structure of the aortic valve and ascending aorta in adults having aortic valve replacement for aortic stenosis versus for pure aortic regurgitation and resection of the ascending aorta for aneurysm. Circulation. 2011;123:896-903.

11. Girdauskas E, Rouman M, Disha K, Espinoza A, Misfeld M, Borger MA, et al Aortic dissection after previous aortic valve replacement for bicuspid aortic valve disease. J Am Coll Cardiol. 2015;66:1409-11.

12. Girdauskas E, Disha K, Rouman M, Espinoza A, Borger MA, Kuntze T. Aortic events after isolated aortic valve replacement for bicuspid aortic valve root phenotype: echocardiographic follow-up study. Eur J Cardiothorac Surg. 2015;48:e71-6.

13. Wojnarski CM, Roselli EE, Idrees JJ, Zhu Y, Carnes TA, Lowry AM, et al Machine-learning phenotypic classification of bicuspid aortopathy. J Thorac Cardiovasc Surg. 2018;155:461-9.e4.

14. Borger MA, Fedak PW, Stephens EH, Gleason TG, Girdauskas E, Ikonomidis JS et al. AATS consensus guidelines on bicuspid aortic valve-related aortopathy: executive summary. J Thorac Cardiovasc Surg. 2018;156:473-80.

15. Robicsek F, Thubrikar MJ, Cook JW, Fowler B. The congenitally bicuspic aortic valve: how does it function? Why does it fail? Ann Thorac Surg. 2004; 77:177-85.

16. Hope MD, Hope TA, Meadows AK, Ordovas KG, Urbania TH, Alley MT, et al Bicuspid aortic valve: four-dimensional MR evaluation of ascending aortic systolic flow patterns. Radiology. 2010;255:53-61.

17. Barker AJ, Markl M, Bürk J, Lorenz R, Bock J, Bauer S, et al. Bicuspid aortic valve is associated with altered wall shear stress in the ascending aorta. Circ Cardiovasc Imaging. 2012;5:457-66.

18. Guzzardi DG, Barker AJ, van Ooij P, Malaisrie SC, Puthumana JJ, Belke DD, et al. Valve-related hemodynamics mediate human bicuspid aortopathy: insights from wall shear stress mapping. J Am Coll Cardiol. 2015;66:892-900.

19. Maredia AK, Greenway SC, Verma S, Fedak PWM. Bicuspid aortic valveassociated aortopathy: update on biomarkers. Curr Opin Cardiol. 2018;33:134-9.

20. Girdauskas E, Disha K, Raisin HH, Secknus MA, Borger MA, Kuntze T. Risk of late aortic events after an isolated aortic valve replacement for bicuspid aortic valve stenosis with concomitant ascending aortic dilation. Eur J Cardiothorac Surg. 2012;42:832-7; discussion 837-8.

21. Svensson LG, Kim KH, Blackstone EH, Rajeswaran J, Gillinov AM, Mihaljevic T, et al. Bicuspid aortic valve surgery with proactive ascending aorta repair. J Thorac Cardiovasc Surg. 2011;142:622-9. 629.e1-3.

22. Hiratzka LF, Creager MA, Isselbacher EM, Svensson LG, Nishimura RA, Bonow RO, et al. Surgery for aortic dilatation in patients with bicuspid aortic valves: a statement of clarification from the American College of Cardiology/American Heart Association task force on clinical practice guidelines. J Am Coll Cardiol. 2016;67:724-31.

23. Sievers HH, Stock S, Stierle U, Klotz S, Charitos EI, Diwoky M, et al. Longer-term results, $\mathrm{z}$ scores, and decision nomograms for treatment of the ascending aorta in 1693 bicuspid aortic valve operations. J Thorac Cardiovasc Surg. 2018;155:549-59.e2.

24. Sievers HH. Everybody is different: a plea for individualizing treatmen of aortopathy. J Thorac Cardiovasc Surg. 2018;156:481-2.

25. David TE. Bicuspid aortic valve with aortic aneurysms. J Thorac Cardiovasc Surg. 2018;156:467-8. 